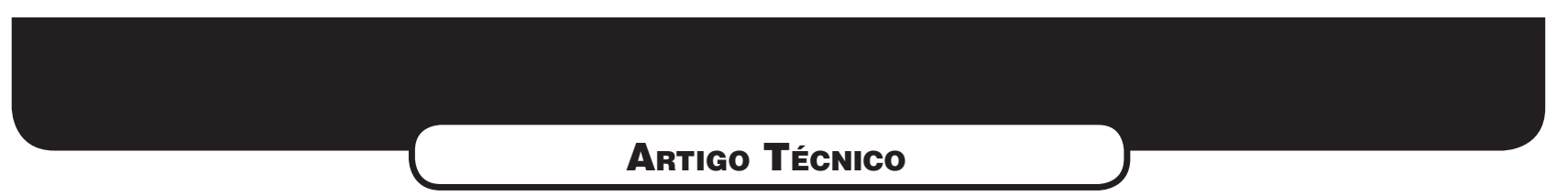

\title{
OtIMIZAÇÃo de PROCESSOS FísICO-Químicos NA REMOÇÃo DE FÓSFORO DE ESGOTOS SANITÁRIOS POR PROCESSOS DE PRECIPITAÇÃO QUÍMICA COM CLORETO FÉRRICO
}

\author{
PhYSICAL-CHEMICAL PROCESS OPTIMIZATION FOR PHOSPHORUS REMOVAL \\ FROM DOMESTIC WASTEWATER BY CHEMICAL PRECIPITATION \\ WITH FERRIC CHLORIDE
}

\begin{abstract}
ANDRÉ LUIZ MARGUTI
Aluno de Graduação do Curso de Engenharia Ambiental pela Escola Politécnica da Universidade de São Paulo

SIDNEY SECKLER FERREIRA FILHO

Engenheiro Civil pela EPUSP. Professor Associado do Departamento de Engenharia Hidráulica e Sanitária da Escola

Politécnica da Universidade de São Paulo

\section{Roque Passos PIVELI}

Engenheiro Civil pela EESC. Professor Associado do Departamento de Engenharia Hidráulica e Sanitária da Escola Politécnica da Universidade de São Paulo
\end{abstract}

Recebido:05/10/07 Aceito: 16/09/08

\section{RESUMO}

Tendo em vista a potencialidade do emprego de processos de coagulação química no tratamento de esgotos, este trabalho teve por objetivo estudar a remoção de fósforo em efluentes de sistemas anaeróbios e aeróbios de tratamento de esgotos. Observou-se que foi possível atingir valores de remoção de fósforo da ordem de $90 \%$, sendo que as dosagens de coagulante se situaram em torno de 60 a $100 \mathrm{mg} \mathrm{FeCl}_{3} / \mathrm{L}$. Concomitantemente com a remoção de fósforo, foi também observada uma remoção de carbono orgânico dissolvido (COD) para os efluentes investigados, sendo que as dosagens de coagulante que permitiram a otimização da remoção de fósforo também possibilitaram a otimização da remoção de COD. Justifica-se a remoção de fósforo na forma orgânica e de polifosfatos pelo fato destes estarem associados ao COD removido.

PALAVRAS-CHAVE: Precipitação química, processos físicoquímicos, coagulação, remoção de fósforo, tratamento de esgotos.

\section{INTRODUÇÃO}

Nas décadas de 40 a 60 , a maior preocupação quando do projeto e construção de estações de tratamento de esgotos (ETEs), especialmente nos Estados Unidos da América e Europa, era a garantia de eficiência na remoção de compostos orgânicos biodegradáveis e sólidos em suspensão totais (SST), sendo que os parâmetros balizadores para tanto eram tão somente a demanda bioquímica de oxigênio (DBO) e SST.

\begin{abstract}
Since chemical coagulation processes are very promising for wastewater treatment, this work looked into phosphorus removal from aerobic and anaerobic systems treating domestic wastewater. It was possible to reach phosphorus removal efficiencies in the order of $90 \%$ for coagulant dosages in the range 60 to $100 \mathrm{mg}$ of ferric chloride per liter. Dissolved organic carbon (DOC) removal in parallel with phosphorus removal was observed for the previously mentioned treatment system effluents. The coagulant dosages for optimized phosphorus removal also led to optimum DOC removal. The removal of organic phosphorus fractions as polyphosphates was justified due its association with the DOC removal by chemical precipitation.
\end{abstract}

KEYWORDS: Chemical precipitation, physical-chemical processes, coagulation, phosphorus removal, wastewater treatment.
No entanto, dada a elevada concentração de nitrogênio e fósforo em esgotos sanitários e, uma vez que os sistemas já implantados não foram originalmente projetados de modo a proporcionarem a sua remoção de forma adequada, a maior parte das instalações construídas a partir da década de 70 teve de ser remodelada com o objetivo de incorporarem processos e operações unitárias que objetivassem a sua remoção de forma satisfatória. Deste modo, considerando a remoção de ambos os nutrientes, enquanto a remoção preferencial de nitrogênio ocorre por via biológica (processos de nitrificação e desnitrificação), a remoção de fósforo em ETEs pode ocorrer por processos biológicos ou por processos físico-químicos mediante o uso de sais de alumínio ou ferro.

De um modo geral, a grande vantagem da adoção de processos físico-químicos de remoção de fósforo em ETEs em relação aos processos biológicos é a sua grande flexibilidade, podendo ser facilmente adaptados em 
unidades já existentes ou quando do projeto de sistemas de tratamento a serem implantados. Os processos biológicos, por sua vez, tendem a apresentar uma maior complexidade operacional por serem altamente dependentes do comportamento da biomassa ativa, das condiçóes ambientais previstas no tanque de aeração e das características do substrato afluente (Marais et al, 1983; Mulkerrins et al, 2004). Portanto, a utilização de processos físico-químicos de remoção de fósforo tem sido vista como alternativa tecnológica bastante promissora, podendo este ser empregado de forma isolada ou conjuntamente com os processos biológicos.

O fósforo em esgotos sanitários pode ser encontrado na forma de fósforo orgânico, quando este está associado a compostos contendo carbono em sua estrutura molecular (P-O-C), podendo este estar na forma dissolvida ou na forma insolúvel. Estima-se que as suas concentrações na forma orgânica não sejam superiores a $10 \%$ da concentração total, o que faz com que a maior parte do fósforo em esgotos sanitários esteja presente na forma de fósforo inorgânico. O fósforo inorgânico em esgotos sanitários preferencialmente encontra-se na forma de fosfatos inorgânicos condensados (ligações P-O-P), tipicamente na forma de polifosfatos ou metafosfatos cíclicos (Rybicki, 1997).

Durante os processos de tratamento de esgotos sanitários anaeróbios e aeróbios, a tendência é que a fração orgânica e os polifosfatos de alto peso molecular sejam hidrolisados e posteriormente transformados a ortofosfatos, sendo este fenômeno de importância significativa quando se considera a opção de sua remoção por processos físico-químicos. Deste modo, em função do estágio do processo de tratamento de esgotos, as espécies fosforadas poderão encontrar-se na forma de polifosfatos condensados e ortofosfatos e, eventualmente, uma pequena fração na forma de fósforo orgânico, sendo que a maior parte destes deverá estar na forma solúvel.

Do ponto de vista termodinâmico, o comportamento do ferro como coagulante em meio aquoso é relativamente complexo, envolvendo a sua participação em reações de hidrólise e precipitação química na forma de hidróxidos e na forma de fosfato férrico. As principais reaçōes físico-químicas do ferro e fósforo na forma de ortofosfato e suas constantes de equilíbrio e produtos de solubilidade estão apresentadas na Tabela 1.

Tabela I - Constantes de equilíbrio e produtos de solubilidade para o ferro e fósforo em meio aquoso (Jensen, 2003)

\begin{tabular}{ccc}
\hline Reação química & $\begin{array}{c}\text { Constante de } \\
\text { equilíbrio }\end{array}$ & $\begin{array}{c}\text { Tipo de reação } \\
\text { química }\end{array}$ \\
\hline $\mathrm{Fe}^{+3}+\mathrm{OH}^{-} \Leftrightarrow \mathrm{Fe}(\mathrm{OH})^{+2}$ & $\mathrm{~K}_{1}=10^{+11,81}$ & Ácido-base \\
$\mathrm{Fe}^{+3}+2 . \mathrm{OH}^{-} \Leftrightarrow \mathrm{Fe}(\mathrm{OH})_{2}^{+}$ & $\mathrm{K}_{2}=10^{+22,33}$ & Ácido-base \\
$\mathrm{Fe}^{+3}+3 . \mathrm{OH}^{-} \Leftrightarrow \mathrm{Fe}(\mathrm{OH})_{3}^{0}$ & $\mathrm{~K}_{3}=10^{+28,4}$ & Ácido-base \\
$\mathrm{Fe}^{+3}+4 . \mathrm{OH}{ }^{-} \Leftrightarrow \mathrm{Fe} \mathrm{OH}$ & $\mathrm{K}_{4}=10^{+34,4}$ & Ácido-base \\
$\mathrm{Fe}(\mathrm{OH})_{3(\mathrm{~s})} \Leftrightarrow \mathrm{Fe}^{+3}+3 . \mathrm{OH}^{-}$ & $\mathrm{K}_{\mathrm{sp} 2}=10^{-37,11}$ & Precipitação \\
$\mathrm{FePO}_{4} \cdot \mathrm{H}_{2} \mathrm{O}_{(\mathrm{s})} \Leftrightarrow \mathrm{Fe}^{+3}+\mathrm{PO}_{4}^{-3}+\mathrm{H}_{2} \mathrm{O}$ & $\mathrm{K}_{\mathrm{sp1}}=10^{-26,4}$ & Precipitação \\
$\mathrm{H}_{3} \mathrm{PO}_{4} \Leftrightarrow \mathrm{H}_{2} \mathrm{PO}_{4}^{-}+\mathrm{H}^{+}$ & $\mathrm{K}_{5}=10^{-2,222}$ & Ácido-base \\
$\mathrm{H}_{2} \mathrm{PO}_{4}^{-} \Leftrightarrow \mathrm{HPO}_{4}^{-2}+\mathrm{H}^{+}$ & $\mathrm{K}_{6}=10^{-7,179}$ & Ácido-base \\
$\mathrm{HPO}_{4} \Leftrightarrow \mathrm{PO}_{4}+\mathrm{H}_{7}$ & $\mathrm{~K}_{7}=10^{-12,375}$ & Ácido-base \\
\hline
\end{tabular}

Desta forma, quando adicionado na fase líquida, o ferro participa de reações de hidrólise, formando espécies mononucleares e polinucleares solúveis e, por ser o $\mathrm{Fe}^{+3}$ insolúvel tanto na forma de hidróxido como na forma de fosfato férrico, o mesmo precipita-se em ambas as formas, podendo a concentração solúvel de $\mathrm{Fe}^{+3}$ ser regida pelo fosfato férrico (Equação 1) ou pelo hidróxido metálico (Equação 2).

$\mathrm{FePO}_{4(\mathrm{~S})} \Longleftrightarrow \mathrm{Fe}^{+3}+$

$+\mathrm{PO}_{4}^{-3} \quad \mathrm{~K}_{\mathrm{sp} 1}=\left[\mathrm{Fe}^{+3}\right] \cdot\left[\mathrm{PO}_{4}^{-3}\right]$

$\mathrm{FePO}_{3(\mathrm{~s})} \Longleftrightarrow \mathrm{Fe}^{+3}+$

$$
+3 . \mathrm{OH}^{-} \quad \mathrm{K}_{\mathrm{sp} 2}=\left[\mathrm{Fe}^{+3}\right] \cdot\left[\mathrm{OH}^{-}\right]^{3}
$$

Para qualquer situação, tem-se que a máxima concentração solúvel de ferro na fase líquida pode ser estimada como sendo a somatória de suas espécies hidrolisadas. Desta forma, tem-se que: $\mathrm{Fe}_{\mathrm{s}}=\left[\mathrm{Fe}^{+3}\right]+\left[\mathrm{FeOh}^{+2}\right]+\left[\mathrm{Fe}(\mathrm{OH})_{2}^{+}\right]$ $+\left[\mathrm{Fe}(\mathrm{OH})_{3}^{0}\right]+\left[\mathrm{Fe}(\mathrm{OH})_{4}^{-}\right]$

$\mathrm{Fe}_{\mathrm{s}}=$ máxima concentração solúvel de ferro na fase líquida $\left(\mathrm{ML}^{-3}\right)$

Explicitando na Equação 3 as concentrações molares de ferro na forma de $\mathrm{Fe}^{+3}$, tem-se que a máxima concentração de ferro solúvel na fase líquida pode ser expresso como:

$\mathrm{Fe}_{\mathrm{s}}=\left[\mathrm{Fe}^{+3}\right] \cdot\left(1+\mathrm{K}_{1} \cdot\left[\mathrm{OH}^{-}\right]+\mathrm{k}_{2}\right.$.

$\left.\left[\mathrm{OH}^{-}\right]^{2}+\mathrm{K}_{3} \cdot\left[\mathrm{OH}^{-}\right]^{3}+\mathrm{K}_{4} \cdot\left[\mathrm{OH}^{-}\right]^{4}\right)$

Caso a solubilidade do ferro seja controlada pelo fosfato férrico, as concentrações de $\mathrm{Fe}^{+3}$ podem ser calculadas de acordo com a Equação (1) e, sendo a mesma substituída na Equação (4), tem-se que:

$$
\begin{aligned}
& \mathrm{Fe}_{\mathrm{s}}=\frac{\mathrm{K}_{\mathrm{SP} 1}}{\left[\mathrm{PO}_{4}^{-3}\right]} \cdot\left(1+\mathrm{K}_{1} \cdot\left[\mathrm{OH}^{-}\right]+\right. \\
& \left.\mathrm{K}_{2} \cdot\left[\mathrm{OH}^{-}\right]^{2}+\mathrm{K}_{3} \cdot\left[\mathrm{OH}^{-}\right]^{3}+\mathrm{K}_{4} \cdot\left[\mathrm{HO}^{-}\right]^{4}\right)
\end{aligned}
$$

Por sua vez, caso a solubilidade do ferro seja controlada pelo hidróxido férrico, as concentraçôes de $\mathrm{Fe}^{+3}$ podem ser calculadas de acordo com a Equação (2) e caso a mesma seja substituída na Equação (4), tem-se que:

$$
\begin{aligned}
& \mathrm{Fe}_{\mathrm{s}}=\frac{\mathrm{K}_{\mathrm{SP} 1}}{\left[\mathrm{OH}^{-}\right]^{3}} \cdot\left(1+\mathrm{K}_{1} \cdot\left[\mathrm{OH}^{-}\right]+\mathrm{K}_{2} .\right. \\
& \left.\cdot\left[\mathrm{OH}^{-}\right]^{2}+\mathrm{K}_{3} \cdot\left[\mathrm{OH}^{-}\right]^{3}+\mathrm{K}_{4} \cdot\left[\mathrm{HO}^{-}\right]^{4}\right)
\end{aligned}
$$

Considerando o balanço de massa para ambos os elementos ferro e fósforo em meio aquoso e postulando-se que a solubilidade do ferro é controlada pelo fosfato férrico, tem-se que, no equilíbrio, pode-se escrever que:

$\mathrm{Fe}_{\mathrm{T}}=\mathrm{Fe}_{\mathrm{s}}+\mathrm{Fe}_{\mathrm{p}}$

$\mathrm{P}_{\mathrm{T}}=\mathrm{P}_{\mathrm{s}}+\mathrm{P}_{\mathrm{p}}$

$\mathrm{Fe}_{\mathrm{T}}$ e $\mathrm{P}_{\mathrm{T}}=$ concentração de ferro e fósforo total na fase líquida $\left(\mathrm{ML}^{-3}\right)$

$\mathrm{Fe}_{\mathrm{s}}$ e $\mathrm{P}=$ concentração de ferro e fósforo solúvel na fase líquida $\left(\mathrm{ML}^{-3}\right)$

$\mathrm{Fe}_{\mathrm{P}}$ e $\mathrm{P}_{\mathrm{p}}=$ concentração de ferro e fósforo precipitado na fase líquida $\left(\mathrm{ML}^{-3}\right)$

Uma vez que $1 \mathrm{~mol}$ de Fe é requerido para a precipitação de $1 \mathrm{~mol}$ de P (Equação 1), tem-se que as concentrações molares de ferro e fósforo precipitado estão associadas entre si, de acordo com a Equação 9.

$\mathrm{P}_{\mathrm{p}}=\mathrm{Fe}_{\mathrm{p}}$

Desta forma, uma vez sendo conhecidas as concentraçóes totais de ferro e fósforo na fase líquida $\left(\mathrm{Fe}_{\mathrm{T}}\right.$ e $\left.\mathrm{P}_{\mathrm{T}}\right)$, tem-se um total de quatro incógnitas $\left(\mathrm{Fe}_{\mathrm{s}}, \mathrm{P}_{\mathrm{s}}, \mathrm{Fe}_{\mathrm{p}}\right.$ e $\left.\mathrm{P}{ }_{\mathrm{p}}\right)$ e quatro equaçóes (Equaçóes $5,7,8^{p}$ e 9), o que permite a determinação dos diagramas de solubilidade do ferro e fósforo para diferentes condiçōes de $\mathrm{pH}$.

No entanto, em face da diversidade das características físico-químicas das águas residuárias em relação a 
águas naturais submetidas ao processo de coagulação, as reaçóes de hidrólise dos sais de ferro e alumínio tendem a serem deformadas pela formação de complexos do ferro e alumínio com outros cátions e ânions presentes em esgotos sanitários, o que faz com que os seus diagramas de solubilidade apresentados na literatura apenas possam ser empregados como uma primeira referência com respeito ao seu comportamento na fase líquida. Além disso, dada a grande dificuldade de serem postulados modelos físico-químicos que permitam a identificação dos mecanismos envolvidos na remoção de fósforo em fase líquida por meio do emprego de sais de ferro e alumínio, torna-se desejável a condução de investigações experimentais (El Samrani et al, 2004).

Os coagulantes podem ser utilizados em diferentes etapas dos sistemas de tratamento de esgotos, podendo ocorrer a montante dos decantadores primários, a montante dos tanques de aeração ou dos decantadores secundários ou como tratamento terciário, ou seja, a jusante do processo biológico aeróbio (Sedlak, 1991; Metcalf \& Eddy, 2003). Mais recentemente, a adoção de processos de precipitação química associada a processos anaeróbios vem sendo, inclusive, objeto de inúmeras pesquisas sendo que Santos (2006) reportam inúmeras aplicaçôes já em escala real, podendo-se citar as ETEs dos municípios de Campinas, Valinhos, Rio Claro e Barra Bonita.

Embora a adoção de processos físico-químicos mediante o uso de sais de ferro e alumínio esteja relativamente bem consolidada do ponto de vista científico na Engenharia Sanitária e Ambiental, faz-se necessária a condução de investigações experimentais que objetivem avaliar qual ou quais são os seus mecanismos preponderantes na remoção de fósforo na fase líquida em esgotos sanitários.

Uma vez que existe uma grande diversidade de possibilidades de aplicação de sais de ferro como coagulantes no tratamento de esgotos sanitários, podendo esta ser efetuada a montante ou a jusante de processos anaeróbios ou aeróbios de tratamento, é interessante que seja avaliado o comportamento dos sais de ferro para diferentes efluentes sob a ótica de remoção de fósforo e carga orgânica.

\section{OBJETIVO}

O objetivo deste trabalho foi estudar, avaliar e otimizar o processo de remoção de fósforo no tratamento de esgotos sanitários, mediante o emprego de processos físico-químicos de precipitação química com o uso de sais de ferro como coagulantes. Deste modo, pretendeu-se mais especificamente:

- Avaliar a remoção de fósforo em efluentes de sistemas anaeróbios e aeróbios de tratamento de esgotos, com a definição de dosagens ótimas de coagulante adequadas à otimização do processo físico-químico de precipitação química.

- Investigar o comportamento do processo de precipitação química na remoção de carga orgânica de forma concomitante com a remoção de fósforo.

- Estudar a especiação química do fósforo presente em esgotos sanitários brutos, efluentes de sistemas anaeróbios e aeróbios de tratamento e seu impacto com respeito à sua remoção por mecanismos de precipitação química.

\section{MATERIAIS E MÉTODOS}

Com o objetivo de permitir um melhor conhecimento dos principais mecanismos envolvidos na remoção de fósforo em esgotos sanitários por processos de precipitação química, a pesquisa foi desenvolvida tendo-se empregado três diferentes tipos de efluentes, a saber:

- Esgoto gradeado e desarenado afluente à ETE Barueri, sendo esta do tipo lodos ativados convencional (Esgoto bruto Barueri).

- Efluente Final produzido pela ETE Barueri (Efluente Final Barueri).

- Esgoto tratado produzido pela ETE Ribeirão Pires, sendo esta do tipo tratamentoanaeróbio, composta por reatores UASB (Efluente Final RP).

Ambas as ETEs estão localizadas na Região Metropolitana de São Paulo (RMSP) e são operadas pela Companhia de Saneamento Básico do Estado de São Paulo (SABESP). As mesmas foram escolhidas por permitirem avaliar o comportamento de diferentes tipos de esgotos sanitários quando submetidos a processos de precipitação química visando à remoção de fósforo. Uma vez que se espera que a especiação do fósforo na fase líquida seja função do tipo de água residuária submetida ao tratamento físico-químico, pretendeuse avaliar qual o comportamento do processo de coagulação na remoção das diferentes fraçōes de fósforo para diversos efluentes. Como a especiação química do fósforo no esgoto bruto é bastante diversa de um efluente produzido por um sistema aeróbio e anaeróbio de tratamento e, dado que poucas informaçōes na literatura apresentam resultados operacionais acerca do comportamento químico do fósforo e do ferro no tratamento de esgotos sanitários brutos, tornou-se interessante a obtenção de resultados experimentais que permitam um melhor conhecimento sobre os aspectos químicos envolvidos nos processos de precipitação química do ferro e fósforo em meio aquoso.

A ETE Ribeirão Pires possui uma vazão média de $40 \mathrm{~L} / \mathrm{s}$ e sua concepção é do tipo tratamento anaeróbio composto por reatores UASB. O tratamento preliminar é composto por unidades de gradeamento e desarenação por meio de caixa de areia aerada sendo o efluente posteriormente encaminhado para quatro reatores UASB que se encontram operando em paralelo. Como a ETE foi concebida sendo composta unicamente por um sistema de tratamento anaeróbio sem pós-tratamento, o efluente final é posteriormente encaminhado para o corpo receptor.

A ETE Barueri é do tipo lodo ativado convencional, apresentando uma vazão média de $9,0 \mathrm{~m}^{3} / \mathrm{s}$. A execução dos ensaios experimentais com o esgoto bruto e tratado proveniente da ETE Barueri possibilitou avaliar a possibilidade de otimização de processos de remoção de nutrientes por meio da adoção de sistemas de tratamento em que o coagulante possa ser adicionado diretamente no tanque de aeração ou em unidades complementares a jusante do sistema biológico aeróbio (tratamento terciário).

Os efluentes bruto e tratado da ETE Barueri empregados na investigação foram coletados a jusante da caixa de areia aerada e após os decantadores secundários, respectivamente. Por sua vez, o efluente tratado proveniente da ETE Ribeirão Pires foi coletado diretamente nas calhas de coleta dos reatores UASB. O programa de amostragem envolveu um total de três coletas para cada efluente, tendo sido os mesmos dispostos em bombonas com capacidade de 20 litros cada, sendo coletado um volume mínimo igual a 40 litros por amostragem para fins de execução dos ensaios experimentais e de caracterização físico-química. Imediatamente 
após a sua coleta, estes eram conduzidos ao Laboratório de Saneamento "Prof. Lucas Nogueira Garcez" para a sua posterior caracterização físico-química. Os principais parâmetros físico-químicos adotados para a caracterização dos efluentes foram $\mathrm{pH}$, carbono orgânico dissolvido (COD), alcalinidade, SST, nitrogênio orgânico e amoniacal, fósforo total suas respectivas frações. Todas as respectivas análises foram efetuadas de acordo com APHA (2005).

Os ensaios experimentais de remoção de fósforo por processos de precipitação química foram conduzidos em escala de "jar-test", tendo-se empregado o cloreto férrico como coagulante. A escolha pelo sal de ferro como coagulante é justificada pelo fato deste permitir a formação de flocos mais densos e com maiores velocidades de sedimentação quando comparado com sais de alumínio. Além disto, ressalta-se que as ETEs recentemente projetadas que possuem processos físico-químicos objetivando a remoção de fósforo foram concebidas para trabalharem com sais de ferro em função de sua melhor adequação quando do uso no tratamento de esgotos (Sinelli, 2002). Para cada ensaio de "jar-test" executado, foi mantida fixa a faixa de $\mathrm{pH}$ de coagulação para cada um dos jarros, tendo-se variado a dosagem de cloreto férrico em cada jarro, de $40 \mathrm{mg} / \mathrm{L}$ a $200 \mathrm{mg} / \mathrm{L}$. O pH de coagulação foi ajustado em cada um dos jarros mediante a adição de volumes de base, de modo que este situasse entre 6,0 a 6,5 , faixa esta que é considerada ótima para a precipitação de fósforo por intermédio da aplicação de sais de ferro como coagulante (Snoeyink et al, 1980; Benjamin, 2002). As soluções de coagulante e base utilizados na condução dos ensaios eram preparadas diariamente e sempre anteriormente à sua execução, sendo que a solução de cloreto férrico era preparada com concentração igual a 10 ou $20 \mathrm{~g} / \mathrm{L}$ de $\mathrm{FeCl}_{3}$.

Os procedimentos adotados para a execução dos ensaios experimentais foram inicialmente à transferência de um volume de 2 litros de amostra para cada um dos jarros do equipamento de “jar-test”. A seguir, a rotação do sistema de agitação era ajustada para cerca de $300 \mathrm{rpm}$ e, imediatamente após seu ajuste, era efetuada a adição do coagulante e base $(\mathrm{NaOH} 1,0 \mathrm{M})$ para a eventual correção do seu $\mathrm{pH}$ de coagulação. A quantificação dos volumes de base requeridos para a correção do $\mathrm{pH}$ de coagulação foi determinada mediante a execução de curvas de titulação específicas para cada amostra e respectiva dosagem de coagulante imediatamente antes da execução dos ensaios de "jartest”. Após 30 segundos de mistura rápida, a rotação era reduzida para $40 \mathrm{rpm}$ e procedia-se a etapa de floculação considerando-se um tempo de mistura lenta igual a 10 minutos. Após este tempo, o equipamento era desligado e permitia-se a sedimentação dos flocos previamente formados por, no mínimo, 10 minutos.

Os parâmetros considerados para a execução dos ensaios de "jar-test" foram adotados e não foram variados, uma vez que não se objetivava a otimização de parâmetros de mistura rápida, floculação e sedimentação, sendo enfocados com mais ênfase os aspectos químicos envolvidos na interação entre o fósforo e ferro em processos de precipitação química. Assim, os resultados experimentais produzidos puderam ser comparados entre si, pois do ponto de vista metodológico, as suas condiçôes operacionais sempre foram mantidas constantes. Após o período de sedimentação, efetuava-se a coleta de 1 litro de amostra em cada jarro para a execução das análises físico-químicas pertinentes.

Para o volume de amostra coletada em cada jarro, eram efetuadas as análises de fósforo total e COD, sendo que, para a análise de COD procedia-se à filtração de um volume de amostra em papel de filtro GF/C (diâmetro médio dos poros igual a $1,2 \mu \mathrm{m}$ ) a fim de que fosse possível eliminação de SST que porventura pudessem causar interferências na técnica analítica.

Uma vez tendo-se analisado o comportamento da remoção de fósforo total para diferentes dosagens de cloreto férrico, para alguns ensaios de "jar-test" específicos, era selecionada uma amostra de modo que fosse possível efetuar a especiação do fósforo presente na fase líquida. Para tanto, um volume de amostra foi submetido à filtração em papel de filtro GF/C e posterior digestão ácida para a determinação de sua concentração de fósforo total dissolvido de acordo com APHA (2005). A diferença entre os valores de concentração de fósforo total e fósforo total dissolvido era assumida como sendo o fósforo presente na forma particulada.

Empregando-se um mesmo volume de amostra filtrada, a mesma foi posteriormente submetida a uma hidrólise ácida a fim de que os polifosfatos solúveis fossem hidrolisados a ortofosfatos solúveis e determinada a sua concentração de ortofosfato solúvel total. Para a mesma amostra, em ausência da etapa de hidrólise ácida, era efetuada a análise de ortofosfato solúvel e a diferença entre ambas as concentrações de fósforo permitiu definir a especiação do fósforo solúvel na forma de ortofosfatos e polifosfatos. Uma vez conhecida à concentração de fósforo dissolvido total (A), orfofosfatos (B) e polifosfatos na forma solúvel (C), o valor de (A-B-C) era admitido como sendo o fósforo dissolvido na forma orgânica.

\section{APRESENTACC̃̃o E ANALISE DOS RESULTADOS}

\section{Esgoto bruto Barueri: remoção de fósforo total e carbono orgânico dissolvido}

As Figuras 1 e 2 apresentam os valores típicos de concentração de fósforo total e carbono orgânico dissolvido (COD) em função da dosagem de coagulante obtido para um ensaio de “jar-test" tendo-se empregado Esgoto Bruto Barueri.

Analisando-se a Figura 1 pode-se notar que a remoção de fósforo observada por mecanismos de precipitação química para o esgoto bruto Barueri foi significativa, sendo que a sua redução atingiu valores em torno de $90 \%$. Observa-se ainda que a remoção de fósforo ocorreu de forma relativamente independente em relação a dosagem de coagulante, uma vez que, para dosagens iguais ou superiores a $40 \mathrm{mg} \mathrm{FeCl}_{3} / \mathrm{L}$, os seus valores de remoção tenderam a um patamar constante. Desta forma, o aumento da dosagem de coagulante não proporcionou uma melhora significativa na remoção de fósforo, o que é benéfico em relação aos aspectos operacionais envolvidos em processos de precipitação química, notadamente com respeito à necessidade de minimização da produção de lodo.

Considerando uma concentração de fósforo total no afluente bruto igual a 9,0 mg P/L, tem-se que a sua concentração molar é igual a $0,29 \mathrm{mM}$. Admitindo uma necessidade mínima de relação molar entre Fe e P da ordem de 


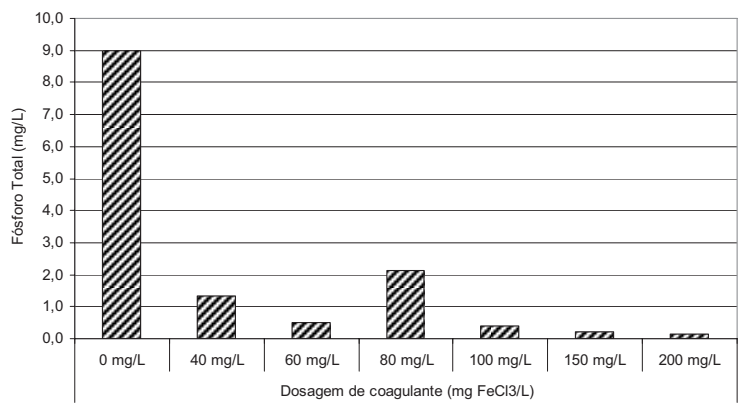

Figura I - Concentração de fósforo total na fase líquida em função da dosagem de coagulante - esgoto bruto Barueri

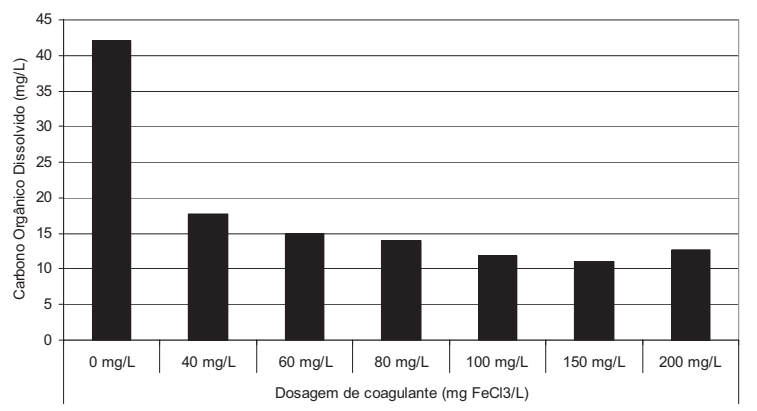

Figura 2 - Concentração de COD na fase líquida em função da dosagem de coagulante - esgoto bruto Barueri
$1: 1$, tem-se que para uma dosagem de $40 \mathrm{mg} \mathrm{FeCl} / \mathrm{L}$ (0,246 $\mathrm{mM}$ expresso como $\left.\mathrm{Fe}^{+3}\right)$, esta se situa em torno de 0,85:1. A alta porcentagem de remoção de fósforo obtida para uma relativa baixa dosagem de coagulante está provavelmente associada à especiação do fósforo presente na fase líquida. Por tratar-se de esgoto bruto, o fósforo presente encontra-se nas formas particulada e solúvel, sendo que na forma solúvel, este pode estar na forma orgânica, na forma de polifosfatos e ortofosfatos. Como é sabido que compostos orgânicos solúveis de alto e médio peso molecular são passíveis de serem removidos por processos de coagulação química, tipicamente por processos de coprecipitação e por adsorção nos flocos de hidróxido formados quando da adição do coagulante na fase líquida, espera-se que o fósforo na forma particulada e associado a compostos orgânicos solúveis de médio a alto peso molecular seja eficientemente removidos por processos de precipitação química. Uma vez tendo sido estes removidos por processos de coprecipitação, a sua eficiência de remoção tenderá a valores constantes e independentemente das dosagens de coagulante aplicado na fase líquida.

Observando-se a Figura 2, nota-se que o mesmo comportamento observado com respeito à remoção de fósforo foi também notado para o parâmetro COD. Com o aumento da dosagem de coagulante, observa-se um aumento na sua remoção, sendo que, a partir de uma dosagem, esta passa a tender a um valor aproximadamente constante. Para o esgoto bruto Barueri, tem-se que a remoção de COD situou-se em torno de $60 \%$ a $70 \%$, valor este que também se comportou de forma relativamente independente em relação à dosagem de coagulante. Os resultados experi- mentais obtidos permitiram concluir que, de um modo geral, as dosagens de coagulante que permitiram a otimização da remoção de fósforo também permitiram simultaneamente a remoção de COD.

Uma vez que a fração de fósforo presente no esgoto bruto na forma de ortofosfato tende a ser relativamente baixa, dado que o fósforo total não se encontra totalmente hidrolisado, postula-se que o seu mecanismo de remoção no esgoto bruto seja por mecanismos de adsorção nos flocos de hidróxido de ferro formados e por coprecipitação. Considerando-se o Efluente Final Barueri, espera-se que o comportamento na remoção de ambos os parâmetros fósforo total e COD seja distinto quando comparado com o esgoto bruto Barueri.

\section{Efluente final Barueri: remoção de fósforo total e carbono orgânico dissolvido}

As Figuras 3 e 4 apresentam os valores típicos de concentração de fósforo total e carbono orgânico dissolvido (COD) em função da dosagem de coagulante obtido para um ensaio de "jar-test" tendo-se empregado o Efluente Final Barueri.

A concentração de fósforo total no Efluente Final da ETE Barueri foi de 5,0 mg P/L e, de modo que fosse possível atingir valores de concentração da ordem de 1,0 mg P/L no efluente tratado por processo de precipitação química, as dosagens de coagulante tiveram de ser superiores a $80 \mathrm{mg} \mathrm{FeCl} / \mathrm{L}$ $\left(0,492 \mathrm{mM}\right.$ expresso como $\left.\mathrm{Fe}^{+3}\right)$.

Comparativamente com o esgoto bruto Barueri, não somente a concentração de fósforo total foi menor, mas também foram maiores as dosagens requeridas de coagulante a fim de que fosse possível atingir valores de fósforo no efluente tratado em torno de 1,0 mg P/L. Dado que a concentração de fósforo para o Efluente Final Barueri foi de 5,0 mg P/L, o que corresponde a uma dosagem de 0,16 mM, tem-se que a relação Fe:P foi de 3:1, considerando-se uma dosagem mínima de $80 \mathrm{mg} \mathrm{FeCl}_{3} / \mathrm{L}$.

Esta relação para o efluente tratado apresentou-se maior do que quando comparado com a obtida para o esgoto bruto Barueri, o que indica uma maior dificuldade na remoção de fósforo para efluentes tratados quando comparado com efluentes em seu estado bruto. Esta maior dificuldade está, muito provavelmente, associada ao fato de que as frações de fósforo no efluente tratado já tendem a apresentar um maior grau de hidrólise e, deste modo, encontram-se preferencialmente na forma de ortofosfatos ou na forma de polifosfatos de baixo peso molecular e que tendem a ser mais dificilmente removidos por processos de coagulação química do que quando comparados com compostos orgânicos de maior peso molecular, tipicamente presentes em afluentes brutos.

Os resultados de remoção de COD apresentados na Figura 4 indicam de forma bastante clara a maior dificuldade de remoção de compostos orgânicos dissolvidos para efluentes tratados quando comparados com efluentes brutos. Como era de se esperar, a concentração de COD para o afluente bruto foi de aproximadamente $42 \mathrm{mg} / \mathrm{L}$, enquanto para o efluente tratado este foi de $18 \mathrm{mg} / \mathrm{L}$, sendo logicamente menor pelo fato da carga orgânica solúvel no efluente bruto ter sido oxidada pelo processo biológico 


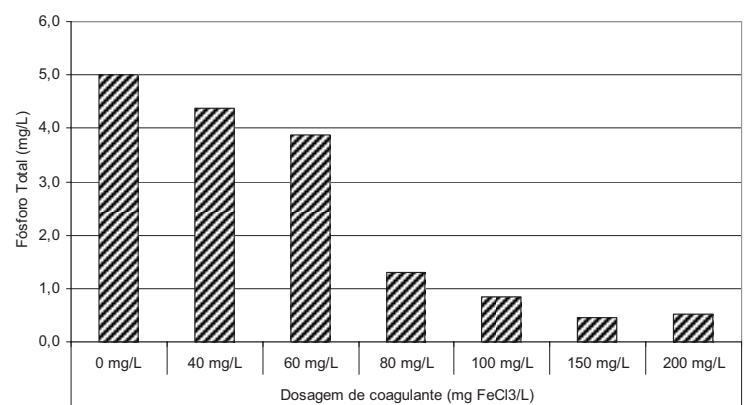

Figura 3 - Concentração de fósforo total na fase líquida em função da dosagem de coagulante - efluente final Barueri

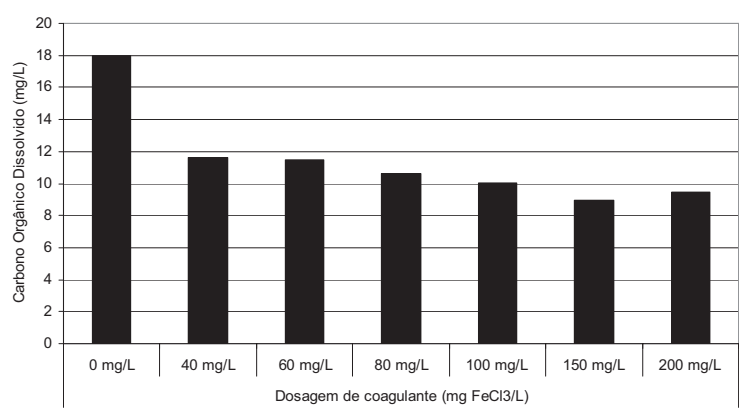

Figura 4 - Concentração de COD na fase líquida em função da dosagem de coagulante - efluente final Barueri

aeróbio de tratamento. Observa-se que, enquanto a redução observada de carga orgânica para o efluente bruto Barueri foi de aproximadamente $60 \%$ a $70 \%$ para dosagens iguais ou maiores que $40 \mathrm{mg} \mathrm{FeCl}_{3} / \mathrm{L}$, a redução para o Efluente Final Barueri não foi superior a 40\%, considerando-se mesmas dosagens de coagulante.

Considerando-se que a fração de compostos orgânicos dissolvidos de médio a alto peso molecular encontrase presente em maior concentração em efluentes brutos do que quando comparado com efluentes tratados, sendo o mesmo submetido a processos de coagulação química, espera-se que a sua remoção seja mais significativa para o bruto em relação ao tratado. A principal justificativa para tanto reside no fato de que, sendo o efluente bruto submetido a processos biológicos aeróbios de tratamento, as suas frações orgânicas de maiores pesos moleculares tenderão a ser hidrolisadas e posteriormente transformadas em compostos orgânicos de menor peso molecular para serem utilizados como fonte de carbono por microrganismos heterotróficos. Desta forma, a característica dos compostos orgânicos dissolvidos presentes nos efluentes tratados de processos bioló- gicos aeróbios de tratamento tendem a apresentar comportamento bastante distinto com relação aos presentes em efluentes brutos, sendo estes compostos primariamente por compostos orgânicos refratários e de difícil biodegradabilidade e por subprodutos metabólicos produzidos pelos microrganismos no tanque de aeração, de baixo peso molecular e de mais difícil remoção por processos de coagulação química.

\section{Especiação química do fósforo e sua remoção para o esgoto bruto e efluente final Barueri}

Com o objetivo de melhor elucidar o efeito da especiação química do fósforo na sua remoção por processos de precipitação química com sais de ferro, as Figuras 5 e 6 apresentam para ambos esgoto bruto e Efluente Final Barueri os valores de concentração de fósforo na fase líquida obtidos para as suas diferentes frações solúveis, considerando uma dosagem de coagulante aplicada igual a $100 \mathrm{mg} \mathrm{FeCl}_{3} / \mathrm{L}$.

Analisando-se as Figuras 5 e 6 conjuntamente, nota-se que o esgoto bruto Barueri apresenta a maior fração solúvel de fósforo na forma de fósforo orgânico, sendo esta em torno de 70\%, ao passo que o Efluente Final Barueri possui a sua maior fração solúvel na forma de ortofosfatos, próximo a $66 \%$. A mudança na especiação química do fósforo para ambos os efluentes bruto e tratado justifica-se pela etapa de hidrólise observada no processo de tratamento aeróbio e posterior transformação das formas de fósforo orgânica para polifosfatos e ortofosfatos solúveis.

Observa-se que, ainda que a maior fração de fósforo solúvel no esgoto bruto esteja na forma orgânica, a sua remoção pode ser considerada satisfatória (95\%), sendo esta justificada pelo fato dos compostos orgânicos fosforados apresentarem peso molecular elevado e serem passíveis de serem removidos por processos de coagulação química. Por sua vez, nota-se que a fração de fósforo orgânica do Efluente Final Barueri, ainda que tenha sido bastante reduzida em relação às demais, mesmo sendo submetida a processos de precipitação química, a sua remoção não foi superior a $40 \%$, o que indica uma maior dificuldade de remoção da fração orgânica de fósforo para efluentes tratados por via aeróbia, uma vez que os compostos orgânicos presentes na fase líquida tendem a apresentarem baixo peso molecular quando comparado com efluentes brutos.

A remoção do fósforo na forma de ortofosfatos e polifosfatos, tanto para o esgoto bruto e Efluente Final Barueri, ocorreram de forma bastante satisfatória, sendo que as suas eficiências de remoção observadas situaram-se em torno de $85 \%$ a $95 \%$. Desta forma, não foram observadas diferenças significativas com respeito a sua eficiência de remoção, ainda que os efluentes apresentem características físico-químicas distintas.

\section{Efluente final Ribeirão Pires: remoção de fósforo total e carbono orgânico dissolvido}

As Figuras 7 e 8 apresentam os valores típicos de concentração de fósforo total e carbono orgânico dissolvido (COD) em função da dosagem de coagulante obtido para o Efluente Final $\mathrm{RP}$, sendo este oriundo do tratamento anaeróbio de esgotos sanitários por reatores UASB.

O comportamento do Efluente Final RP no tocante a remoção de 


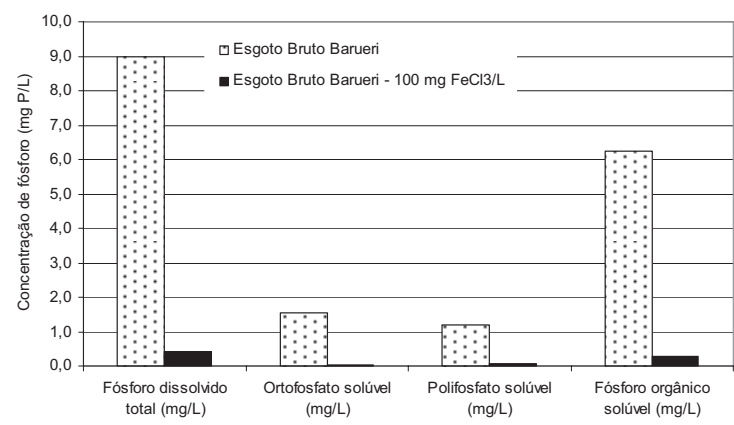

Figura 5 - Concentração de fósforo na fase líquida para as suas diferentes frações solúveis - esgoto bruto Barueri

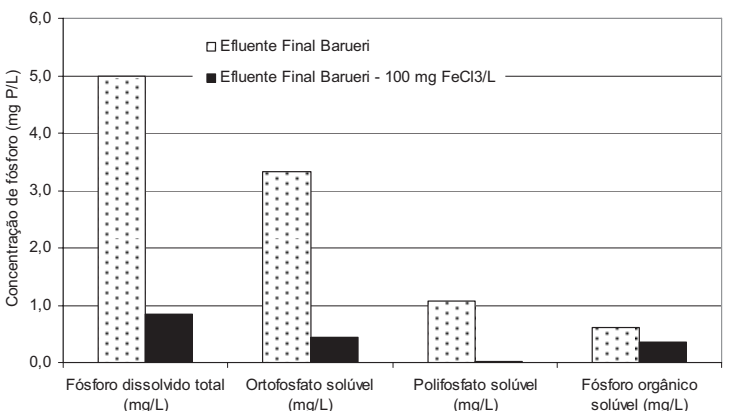

$(\mathrm{mg} / \mathrm{L})$

$(\mathrm{mg} / \mathrm{L})$

solúvel $(\mathrm{mg} / \mathrm{L})$

Figura 6 - Concentração de fósforo na fase líquida para as suas diferentes frações solúveis - efluente final Barueri fósforo e COD foi bastante similar quando comparado com o Efluente Final Barueri. Analisando-se os resultados de fósforo obtidos para os ensaios de precipitação química conduzidos para diferentes dosagens de coagulante e apresentados na Figura 5 tem-se que para dosagens iguais ou superiores a $60 \mathrm{mg} \mathrm{FeCl} / \mathrm{L}$ foi possível a obtenção de concentraçôes de fósforo na fase líquida inferiores a $1,0 \mathrm{mg} \mathrm{P} / \mathrm{L}$. Considerando que a concentração de fósforo no Efluente Final RP foi igual a 4,0 mg/L, o que corresponde a uma dosagem igual a $0,13 \mathrm{mM}$, e admitindo-se uma dosagem de $60 \mathrm{mg} \mathrm{FeCl} / \mathrm{L}$ $\left(0,369 \mathrm{mM}\right.$ expresso como $\left.\mathrm{Fe}^{+3}\right)$ como adequada a fim de que seja possível atingir valores de fósforo total inferiores a $1,0 \mathrm{mg} \mathrm{P} / \mathrm{L}$, tem-se que a relação Fe:P situou-se em torno de 2,86:1, muito próxima quando comparado com o efluente final Barueri.

Também se observa que, com o aumento da dosagem de coagulante, uma vez tendo sido atingido um valor de concentração de fósforo no efluente tratado em torno de $1,0 \mathrm{mg} / \mathrm{L}$, o benefício auferido com respeito à remoção de fósforo é bastante reduzido, não se justificando a aplicação de dosagens superiores a $60 \mathrm{mg} \mathrm{FeCl} / / \mathrm{L}$. A remoção de COD seguiu o mesmo comportamento quando comparado com o esgoto bruto e Efluente Final Barueri, sendo que as suas eficiências de remoção situaramse em torno de $65 \%$ e invariáveis em relação à dosagem de coagulante.

\section{Especiação química do fósforo e sua remoção para o efluente final Ribeirão Pires}

Com respeito à remoção das diferentes fraçôes solúveis de fósforo observadas para o Efluente Final RP, a Figu-

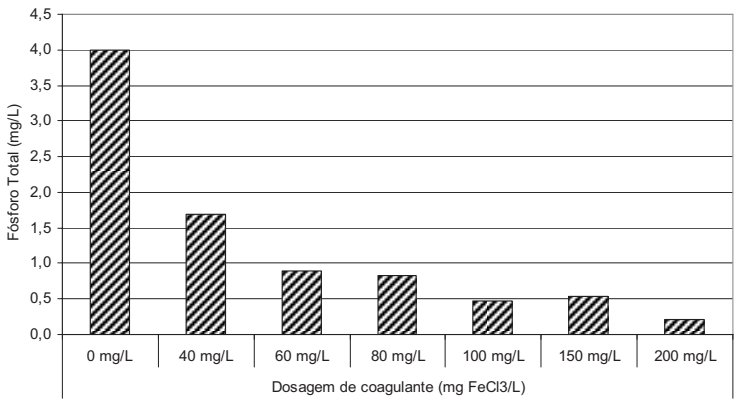

Figura 7 - Concentração de fósforo total na fase líquida em função da dosagem de coagulante - efluente final $R P$

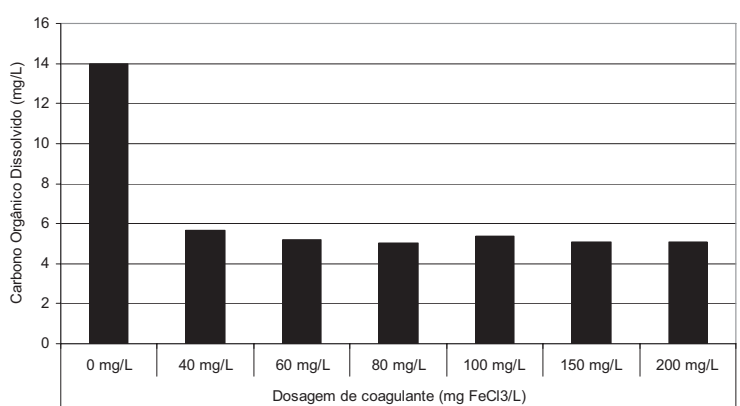

Figura 8 - Concentração de COD na fase líquida em função da dosagem de coagulante - efluente final $R P$

ra 9 apresenta os valores de concentração de fósforo na fase líquida obtidos, considerando uma dosagem de coagulante aplicada igual a $100 \mathrm{mg}$ $\mathrm{FeCl}_{3} / \mathrm{L}$.

Os resultados experimentais apresentados na Figura 9 indicam que todas as frações solúveis de fósforo (orgânico, polifosfatos e ortofosfatos) são eficientemente removidas por processos de precipitação química, tendo sido observadas valores de remoção da ordem de $80 \%$ a $95 \%$. A maior eficiência na remoção da fração orgânica de fósforo solúvel observada para o Efluente Final RP quando comparado com o Efluente Final Barueri deve-se ao fato de que o processo anaeróbio, embora permita uma remoção de carga orgânica em torno de $60 \%$ a $70 \%$, não é suficientemente capaz de permitir a hidrólise das formas orgânicas solúveis de fósforo e sua posterior transformação em compostos orgânicos de menor peso molecular, o que faz com que o fósforo orgânico presente em efluentes oriundos de processos anaeróbios seja passível de maior remoção do que quando comparado com efluentes provenientes de processos aeróbios.

De um modo geral, para todos os efluentes considerados na investigação experimental, uma vez tendo sido otimizadas as dosagens de coagulante a 


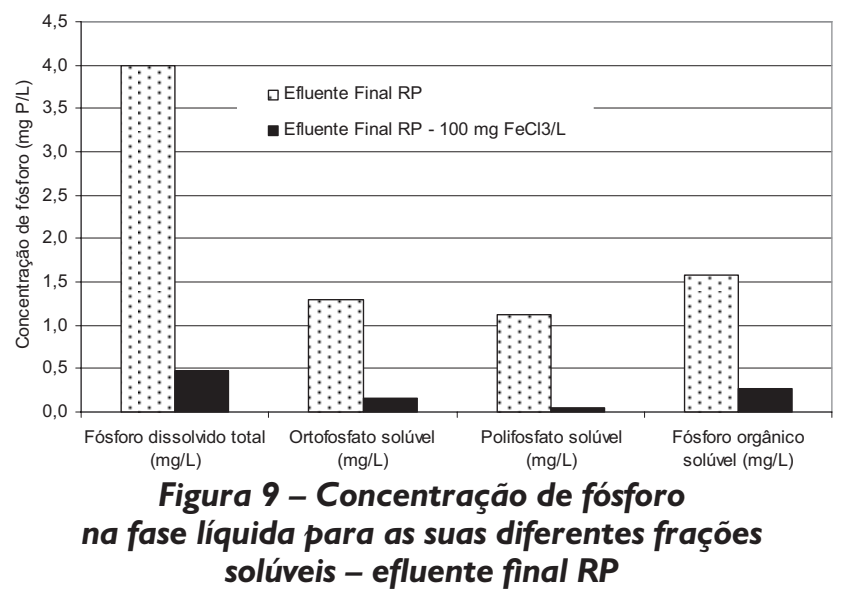

fim de que fosse possível a maximização da remoção de fósforo na fase líquida, conseqüentemente foi também possível a otimização da remoção de COD. Nota-se que, inclusive, que o controle da dosagem de coagulante foi controlado pela otimização da remoção de fósforo e não pela otimização da remoção de COD. Uma vez que a operação de sistemas de tratamento terciário possui como objetivo a remoção de nutrientes, as dosagens de coagulante deverão ser ditadas pela maximização da remoção de fósforo, sendo que a remoção de COD é considerada como incidental, não sendo objeto de otimização.

\section{Comportamento químico do ferro e fósforo em meio aquoso e sua remoção por processos de precipitação química}

Com o objetivo de analisar o comportamento do Fe e P na fase líquida, mediante o emprego das equações 5, 7, 8 e 9, é possível a determinação de seus diagramas de solubilidade, sendo que as Figuras 10 e 11 apresentam os valores de concentração de ferro e fósforo solúvel na fase líquida para uma relação molar de Fe e P igual a 1:1.

Uma vez que as dosagens mínimas requeridas de ferro a serem aplicadas na fase líquida para a remoção de fósforo deverão obedecer a uma relação molar de Fe e P igual a 1:1 (Equação 1), tem-se que para esta relação molar a solubilidade do ferro na fase líquida (Figura 10) é governado pelo hidróxido metálico para valores de $\mathrm{pH}$ na fase líquida superior a 5,5. Como dificilmente a operação de processos de coagulação tenderá a ser realizada com valores de $\mathrm{pH}$ inferiores a este valor, espera-se que, em qualquer situação, ocorra a formação de hidróxidos metálicos de ferro formados juntamente com espécies de fósforo precipitados na forma de fosfato férrico.

A remoção de fósforo (Figura 11) ocorre de forma eficiente para uma ampla faixa de $\mathrm{pH}$, sendo esta em torno de 5 a 8 , não se evidenciando uma diminuição da mesma para valores de $\mathrm{pH}$ em que tipicamente se procede a operação de processos de precipitação química.

De acordo com a literatura (Snoeyink et al, 1980; Metcalf \& Eddy, 2003), tem-se que a remoção de fósforo inorgânico solúvel na fase líquida por intermédio de sais de ferro é otimizada quando o valor de $\mathrm{pH}$ situa-se em torno de 5,5 a 6,5, no entanto, os resultados de fósforo solúvel apresentados na Figura 11 indicam que, embora as menores concentraçóes solúveis de fósforo são obtidas quando o $\mathrm{pH}$ do processo de coagulação situa-se nesta faixa de 5,0 a 6,5, ainda sim, para maiores valores deste, a sua eficiência de remoção continua sendo bastante elevada, decrescendo apenas para valores de $\mathrm{pH}$ superiores a 8,5 .

Como se observa que as dosagens molares requeridas de $\mathrm{Fe}$ em relação a $\mathrm{P}$ são maiores do que $1: 1$, as Figuras 12 e 13 apresentam os valores de concentração de ferro e fósforo solúvel na fase líquida para uma relação molar de Fe e P igual a 2:1. A relação molar de Fe e P igual a 2:1 foi selecionada uma vez ter sido observado na prática a necessidade de precipitação de parte do ferro adicionado na forma de hidróxido férrico, a fim de esta fase sólida permita a remoção por sedimentação do fósforo precipitado na forma de fosfato férrico.

Analisando-se os valores de ferro solúvel apresentados na Figura 12, notase que, independentemente do $\mathrm{pH}$, a solubilidade do ferro na fase líquida é inteiramente controlada pelo hidróxido férrico. Isto implica que, qualquer que seja o mecanismo de remoção de fósforo na fase líquida, deverá estar presente em meio aquoso hidróxido férrico precipitado e a sua formação tenderá a ser de fundamental importância a fim de que as fraçōes de fósforo particulado, orgânico solúvel e polisfosfatos de alto peso molecular possam ser removidos por mecanismos de coprecipitação e adsorção na fase sólida formada (Galarneau et al, 1997).

Comparando-se os valores de solubilidade do fósforo na fase líquida para diferentes relaçóes molares de $\mathrm{Fe}$ e P (Figura 11 e 13), nota-se que a sua solubilidade permanece relativamente inalterada, sendo esta independente da dosagem de Fe aplicada em relação a $\mathrm{P}$ e, qualquer que seja o $\mathrm{pH}$ da fase líqui$\mathrm{da}$, caso este esteja situado entre 5,5 a 8,5 , as concentraçôes de fósforo solúvel tenderão a serem bastante reduzidas.

Os resultados experimentais obtidos de remoção de fósforo para os diferentes efluentes e respectivas frações dissolvidas (Figuras 5, 6 e 9) indicam que, não somente a forma de ortofosfatos pode ser removida de forma eficiente, mas também o fósforo na forma orgânica e os polifosfatos. Uma vez que as relações molares aplicadas de Fe e P sempre foram superiores a 1 e, concomitantemente com a remoção de fósforo, também ocorreu a remoção de COD, postula-se que a remoção do fósforo na forma de polifosfatos e fósforo orgânico foi uma conseqüência direta da remoção de parte da fração de COD na fase líquida.

Ressalta-se que a formação e presença de flocos de hidróxido férrico são de suma importância na operação de processos de remoção de fósforo por processos de precipitação química, uma vez que a dosagem de coagulante também tem que ser otimizada a fim de que os flocos formados possam ser removidos de forma eficiente por processos de separação sólido-líquido, podendo estes ser por sedimentação gravitacional ou flotação por ar dissolvido. Neste caso, tem-se que, muitas vezes, a dosagem de Fe é relativamente maior do que a requerida para a remoção de fósforo uma vez que há a necessidade de formação de flocos relativamente densos e com massa específica adequada a fim de que estes possam ser passíveis de remoção eficiente por processos tradicionais de separação sólido-líquido. 


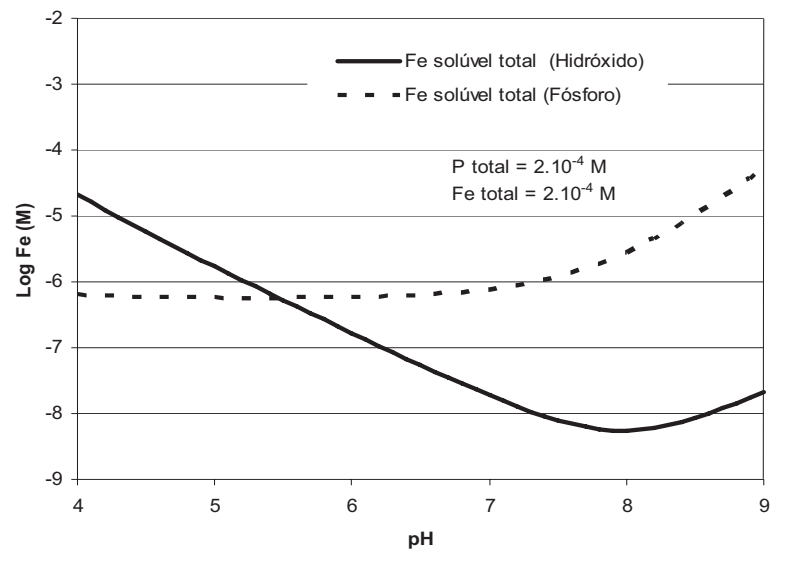

Figura 10 - Solubilidade do ferro na fase líquida para uma relação molar Fe:P igual a I:I

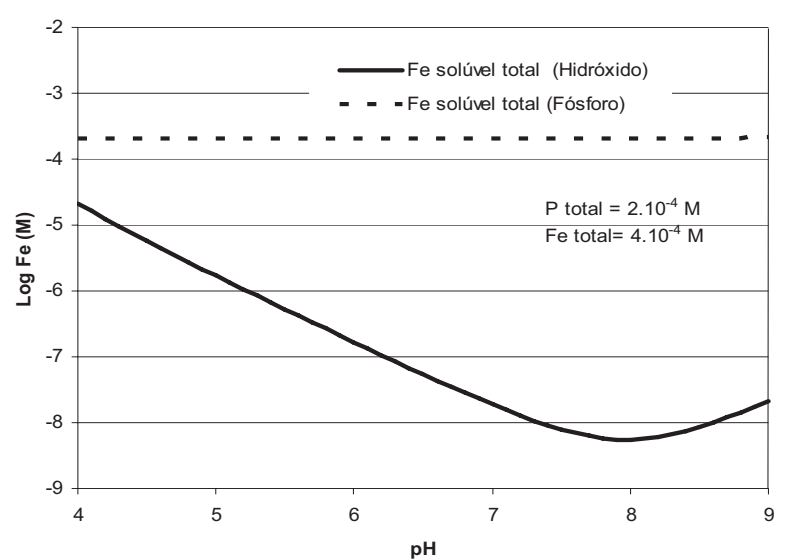

Figura 12 - Solubilidade do ferro na fase líquida para uma relação molar Fe:P igual a 2:I

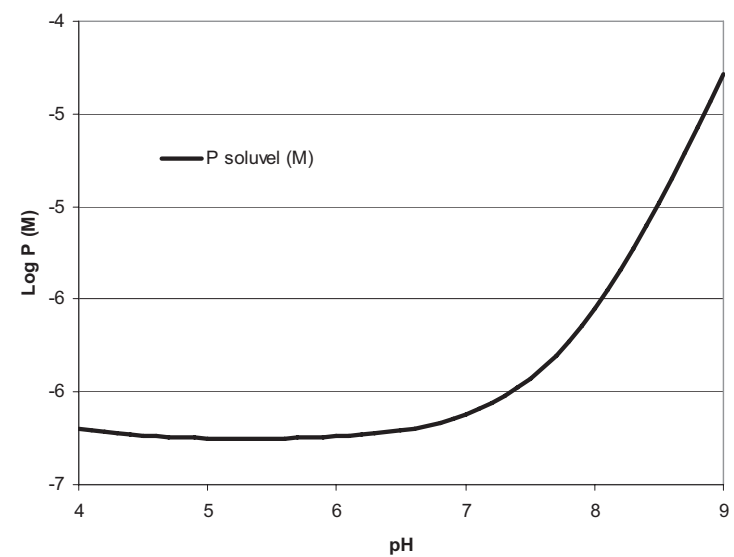

Figura II - Solubilidade do fósforo na fase líquida para uma relação molar Fe:P igual a I:I

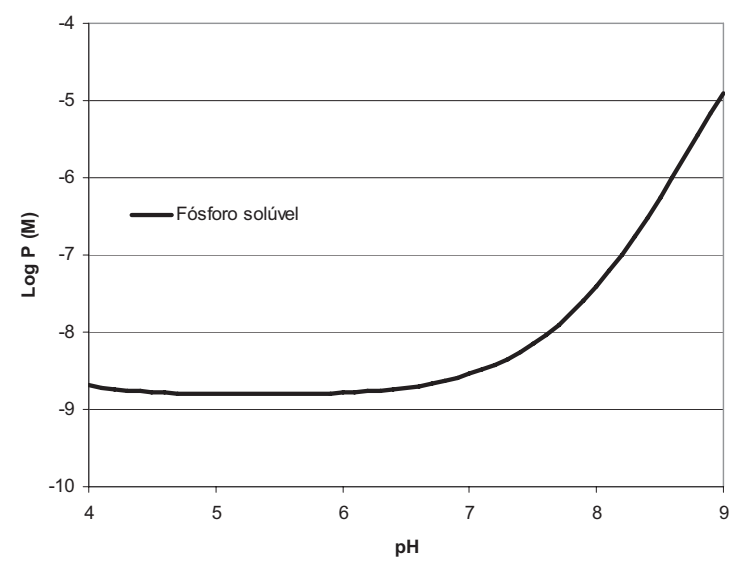

Figura I 3 - Solubilidade do fósforo na fase líquida para uma relação molar Fe:P igual a 2:I

\section{CONCLUSÕES E RECOMENDAÇỖES FINAIS}

Com base nos resultados experimentais, pode-se concluir que:

- Foi possível a obtenção de valores de remoção de fósforo para efluentes bruto e tratado da ordem de $90 \%$ para dosagens de sais de ferro iguais ou superiores a $60 \mathrm{mg} \mathrm{FeCl} / \mathrm{L}$, sendo que as relações molares ótimas de Fe:P situaram entre $2: 1$ a $3: 1$.

- Concomitantemente com a remoção de fósforo, observou-se uma significativa remoção de COD, sendo que os seus valores de remoção foram da ordem de $60 \%$ a $70 \%$ para esgoto bruto e efluente de reator UASB e em torno de $40 \%$ para efluente tratado por lodo ativado convencional.

- Uma vez tendo-se definido as dosagens ótimas a fim de que fosse possível a otimização da remoção de fósforo por processos de precipitação química, também estas foram consideradas adequadas para a otimização da remoção de COD.

- Para relaçôes molares Fe:P iguais ou superiores a 1:1, a solubilidade do ferro é controlada pelo hidróxido metálico e a sua formação é a principal responsável pela remoção das frações de fósforo dissolvido na forma orgânica e polifosfatos associados a compostos orgânicos de médio a alto peso molecular.

- A remoção de fósforo na forma de ortofosfatos ocorre preferencialmente por mecanismos de precipitação na forma de fosfato férrico ou pela sua adsorção no hidróxido metálico previamente formado, devendo ser efetuados estudos complementares com o objetivo de dirimir as dúvidas ainda existentes.

\section{AGRADECIMENTOS}

A FAPESP (Fundação de Amparo a Pesquisa do Estado de São Paulo) pelo apoio financeiro concedido (Processo
2006/55702-6) e Bolsa de Iniciação Científica (Processo 2006/55703-2).

\section{REFERÊNCIAS}

APHA, AWWA, WEF. Standard Methods for the Examination of Water and Wastewater. $21^{\circ}$ ed. Washington, D.C., USA, 2005.

BENJAMIN, M.M. Water chemistry. 668 p. New York, McGraw Hill, 2002.

EL SAMRANI, A.G et al. Clarification of Municipal Sewage with Ferric Chloride: The Nature of Coagulant Species. Water Research, v.38, n.3, p.756-768, 2004.

GAlarneaU, E.; GEHR, R. Phosphorous Removal From Wastewaters: Experimental and Theoretical Support for Alternative Mechanisms. Water Research, v.31, n.2, p. 328-338, 1997.

JENSEN, J.N. A problem solving approach to aquatic chemistry. New York, John Wiley \& Sons, 585p, 2003.

MARAIS, G. Observation supporting phosphate removal by biological excess uptake - a review. Water Science \& Technology, v.15, p.15-41, 1983.

METCALF \& EDDY. Wastewater Engineering: Treatment, Disposal, Reuse. McGraw-Hill, 4a edição, 2005. 
MULKERRINS, D.; DOBSON, A.D.W.; COLLERAN, E. Parameters affecting biological phosphate removal from wastewater. Environment International, 30, p.249-259, 2004.

RYBICKI, S. Phosphorus removal from wastewater. A literature review. Royal Institute of Technology, Stochholm, 106p, 1997.

SANTOS, H.R. Coagulação/Precipitação de efluentes de reator anaeróbio de leito expandido e de sistema de lodo ativado precedido de reator UASB, com remoção de partículas por sedimentaçãa ou flotação. Tese (Doutorado) - Escola de Engenharia de São Carlos da USP. São Carlos, 2006.

SEDLAK, R. Phosphorus and Nitrogen Removal from Municipal Wastewater: Principles and Practice. Lewis Publishers, 2a edição, 1991.

SINELLI, P.H. Remoção de Fósforo de Efluente de Tratamento Anaeróbio por Processo Físico-Químico. Dissertação (Mestrado) - Escola Politécnica da USP. São Paulo, 2002.

SNOEYINK, V.L., JENKINS, D. Water chemistry. New York, John Wiley \& Sons, 463p, 1980 .

\section{Endereço para correspondência:}

Sidney Seckler Ferreira Filho

Departamento de Engenharia

Hidráulica e Sanitária

Escola Politécnica da

Universidade de São Paulo

Av. Prof. Almeida Prado, Travessa

2, n.27 I - Prédio de Engenharia

Civil

Cidade Universitária

CEP 05508-900 São Paulo - SP

- Brasil

Telefone: (I I) 309I-5220

E-mail: ssffilho@usp.br 